\title{
Recurrent Grade 1 Follicular Lymphoma
}

National Cancer Institute

\section{Source}

National Cancer Institute. Recurrent Grade 1 Follicular Lymphoma. NCI Thesaurus. Code C8155.

The reemergence of grade 1 follicular lymphoma after a period of remission. 